\title{
Application Work Using Software Tools and Didactic Electrical Machines Equipment in Electrical Engineering Studies
}

\author{
Marcel Torrent, Eusebi Martinez, José I. Perat
}

\begin{abstract}
This article describes the use of software tools and didactic equipment of electrical machines applied to the teaching in Electrical Engineering, specifically in the realization of an application work consisting of the characterization of the threephase induction motor.

Several studies have explored the effectiveness of teaching activities, which encompass different learning tools in the same work, from the use of didactic materials to the use of professional computer tools.

The objective is the simultaneous use of didactic equipment and the calculation methodologies through specific software of industrial applications in engineering studies.

In addition, to observe whether performing application work that implementing different techniques at the same time fosters the critical spirit among students.

The activities students must do in the application work proposed in the subject of rotating electrical machines is to determine all the constructive variables of an induction motor, draw it, simulate its electromagnetic behavior by finite elements method with a freeware available 2D program, test the motor in the laboratory following the guidelines of the current standards and, finally, compare the results obtained from the tests and the simulation, by making a critique of the results and the calculation methodology used.

The application work presented in the article has been implemented during several courses in the subject of electrical machines for Electrical Engineering students, with satisfactory results.
\end{abstract}

Index Terms - Software tools, didactic equipment, electrical engineering, finite element method simulation, evaluation rubric.

\section{INTRODUCTION}

$\mathrm{I}_{\mathrm{E}}^{\mathrm{N}}$ $\mathrm{N}$ the process of students learning in the field of Engineering, different practical activities are complemented by using material for didactic purposes, industrial equipment, measuring equipment or computer tools, such as simulation programs and spreadsheets, among other possibilities [1] [2].

In the particular case of Electrical Engineering, there is practically consensus among the educational community that the realization of laboratory practices is a must for student's training. Even so, in many occasions, the economic limitations for the acquisition of material, the limitations of laboratory availability, the necessary safety conditions during the use of laboratory material when working with electrical voltage and the little time flexibility in the academic calendar of students,

The authors are professors within the Department of Electrical Engineering of Escola Politècnica Superior d'Enginyeria de Vilanova i la Geltrú, Universitat Politècnica de Catalunya (e-mail: mtorrent@ee.upc.edu). makes practices be carried out in a limited duration and controlled extension within excessive rigid sessions, an issue limiting the realization of extensive practical work within the subject regulated classroom schedule [3] [4].

Of equal interest is the introduction of simulation practices using computer programs, which are more flexible in their implementation than laboratory practices, since students can supplement these simulations out of their strict in-person schedule. This has, sometimes, caused the danger of abusing of simulation practices to the detriment of laboratory practices with real material [5] [6] [7].

This article presents an application work proposed to students and within the same activity, it includes the experimental realization of tests in the laboratory, the realization of simulations through computer programs, the need to consult current standards, the elaboration of calculation spreadsheets to obtain results and the criticism of those results to be developed in a final report of marked technical nature.

In order to be able to implement this work, of considerable temporary dedication by the student within the framework of a subject, it is necessary to schedule some face-to-face sessions during the course, both in the laboratory and in computer sessions; and also within the assigned hours in the classroom, in addition to the personal work that students must devote out of their classroom hours [8] [9].

This paper is organized as follows. After this introduction, in Section 2, a description of the used induction motor is shown, with the results obtained in the laboratory tests, the finite element simulations and the characteristic curves from the circuit equivalent analysis. The implementation work presented and applied in the Electrical Engineering studies is exposed in Section 3. Students feedback and the evaluation rubric of the application work in several courses is reported in Section 4. Finally, in Section 5, the main conclusions are presented.

\section{CHARACTERIZATION OF THE THREE-PHASE INDUCTION MOTOR}

The scope of the application work proposed to students is the characterization of a three-phase induction motor [10], using didactic equipment of electrical machines available in the laboratory. That didactic equipment, by means of the assembly of different pieces and coils, allows to set up different types of rotating electrical machines and different windings for the same type of machine [11]. 
In this section, the different parts of the application work and the results that can be obtained during its realization are shown. Section III specifies how these application work parts are implemented during the course.

\subsection{Induction Motor Used}

In Figure 1, a photograph of the parts of the induction motor used for didactic purposes is shown. The first activity is to write down all the main dimensions of the motor, with the help, in some cases, of the equipment user's manual. The main dimensions are shown in Table 1 [12]. The second activity consists of assembling the motor parts, making a three-phase stator winding, double-layer, four poles and a star connection, Figure 2.

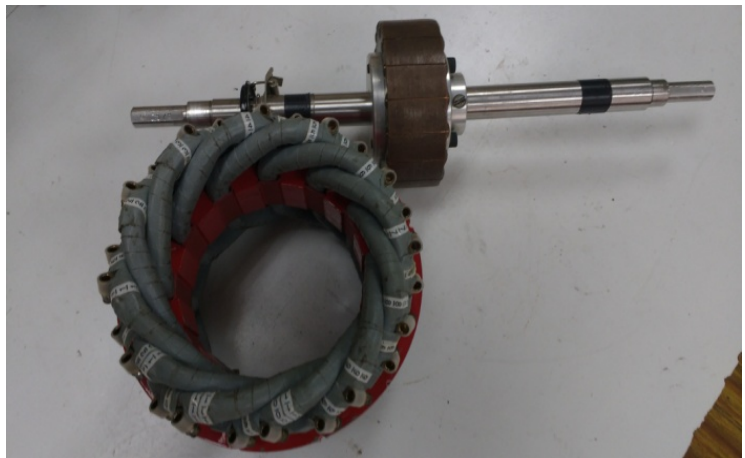

Figure 1. Stator and rotor of the induction motor corresponding to the didactic equipment [7].

TABLE 1

MAIN DIMENSIONS OF THE MOTOR

\begin{tabular}{ll}
\hline \multicolumn{1}{c}{ Dimensions } & Quantity \\
\hline Stator exterior diameter & $237.4 \mathrm{~mm}$ \\
Stator inner diameter & $101.5 \mathrm{~mm}$ \\
Rotor exterior diameter & $100.5 \mathrm{~mm}$ \\
Induced length & $33.5 \mathrm{~mm}$ \\
Number of stator slots & 12 \\
Number of rotor slots & 17 \\
Number of turns in the stator coils & 195 \\
Magnetic sheet & Ferrosil 216 \\
Axis diameter & $20.5 \mathrm{~mm}$ \\
\hline \hline
\end{tabular}

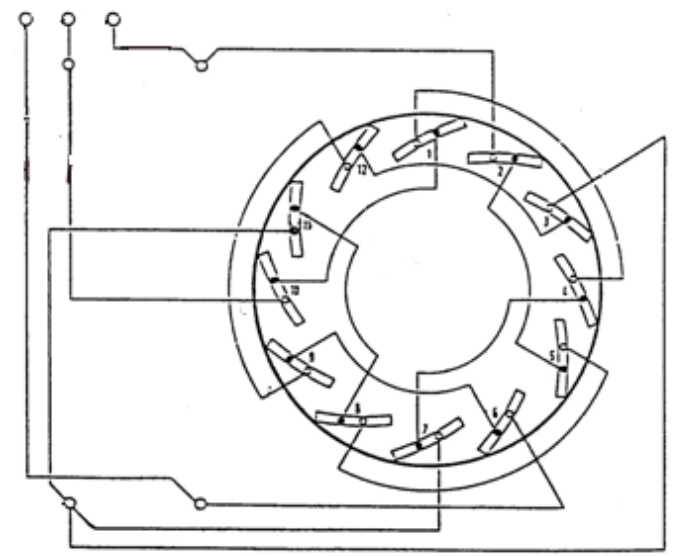

Figure 2. Three-phase stator winding, four poles, star connection [7]

\subsection{Laboratory Tests}

Once the different parts have been assembled and the windings are connected, the motor is tested in the laboratory of electrical machines. First, the existence of the rotating magnetic field generated by the stator windings is checked by a compass. The speed is measured as shown in Figure 3.

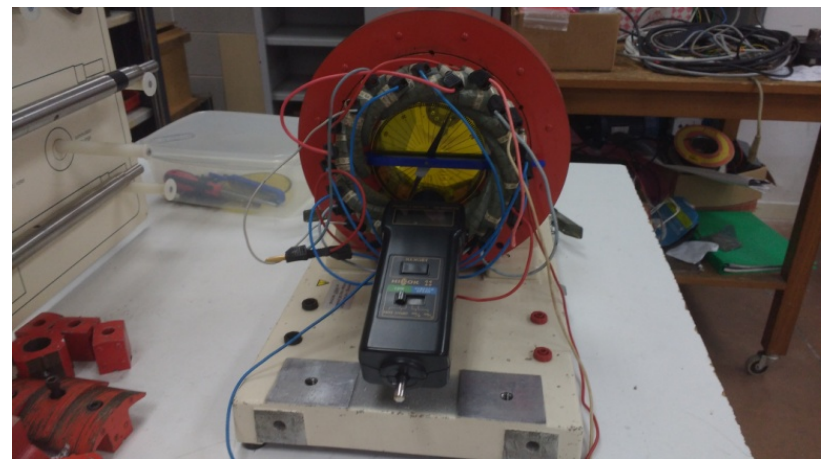

Figure 3. Check and speed measuring of the rotating magnetic field.

Subsequently, we proceed to determine the parameters of its equivalent circuit according to Figure 4, where:

$\mathrm{R}_{1}=$ stator resistance

$\mathrm{R}_{2}{ }_{2}=$ rotor resistance referred to stator

$\mathrm{X}_{\mathrm{d} 1}=$ stator reactance

$\mathrm{X}_{\mathrm{d} 2}^{\prime}=$ rotor reactance referred to stator

$\mathrm{X}_{\mu}=$ magnetizing reactance

$\mathrm{R}_{\mathrm{fe}}=$ iron loss resistance

$\mathrm{s}=\operatorname{slip}$

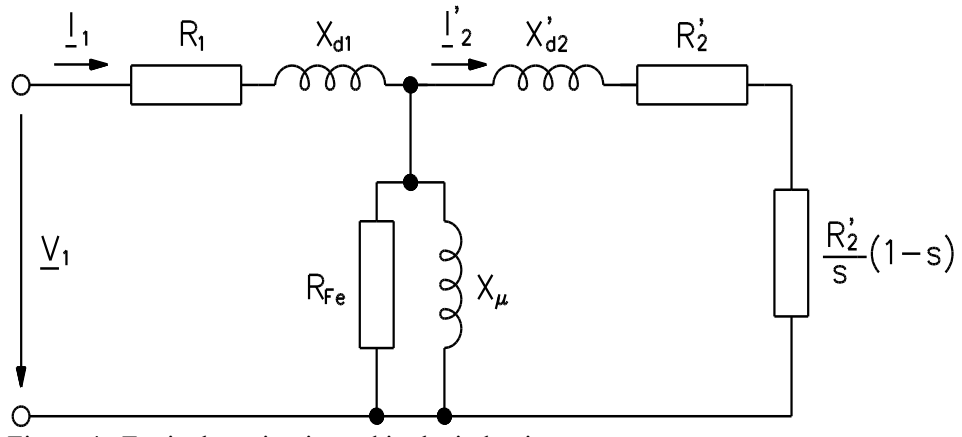

Figure 4. Equivalent circuit used in the induction motor

The tests are carried out by following the indications of the IEC60034-2-1 standard [13], and the students should consult and apply. Specifically, the measurement of the stator resistance, the no load test for different stator voltages and the short-circuit test are carried out. From the instructions in the manual for the use of the didactic equipment, a nominal voltage of $200 \mathrm{~V}$ and a nominal current of $1 \mathrm{~A}$ are established. The assembly carried out in the laboratory, with the motor and measuring equipment, is shown in Figure 5 [14]. 


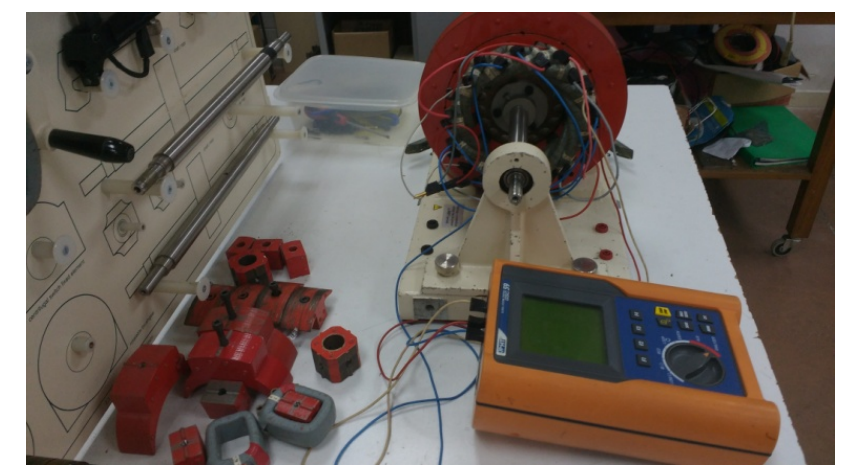

Figure 5. Measuring equipment to perform the tests on the assembly induction motor.

By applying the calculation procedure of the standard, the parameters of the equivalent circuit obtained, for the frequency of $50 \mathrm{~Hz}$, are shown in Table 2 [15].

TABLE 2

EQUIVALENT CIRCUIT PARAMETERS OBTAINED FROM THE LABORATORY

\begin{tabular}{ll}
\multicolumn{2}{c}{ TESTS } \\
\hline \hline \multicolumn{1}{c}{ Parameter } & Value \\
\hline Stator resistance & $16.45 \Omega$ \\
Rotor resistance referred to stator & $15.58 \Omega$ \\
Stator reactance & $21.43 \Omega$ \\
Rotor reactance referred to stator & $21.43 \Omega$ \\
Magnetizing reactance & $106.16 \Omega$ \\
Iron loss resistance & $3352.71 \Omega$ \\
\hline \hline
\end{tabular}

\subsection{Finite Elements Method Simulation}

Based on the knowledge of all constructive variables and materials of the motor, simulations are carried out using the finite elements method [16] [17]. The FEMM (Finite Element Method and Magnetics) program is used, freeware 2D simulation program [18].

The simulations that must be done are:

- Ferromagnetic material in the stator and in the rotor, and nominal current in one phase of the motor, Figure 6. This simulation allows to obtain the magnetizing inductance and the longitudinal resistance of the stator.

- Ferromagnetic material in the stator and air in the rotor, and nominal current in one phase of the motor, Figure 7. This simulation allows, in an approximate way, to obtain the stator leakage inductance.

- Ferromagnetic material in the rotor and air in the stator, and nominal current in a bar of the rotor cage, Figure 8. This simulation allows, in an approximate way, to obtain the leakage inductance and the longitudinal resistance of a rotor bar.

- Cross section to determine the effect of coil heads, and nominal current in a stator coil, Figure 9. Giving the figure the expected depth of the coil head effect, this simulation approximately allows to obtain the leakage inductance and resistance of coil heads.



Figure 6. Simulation to determine the magnetizing inductance.

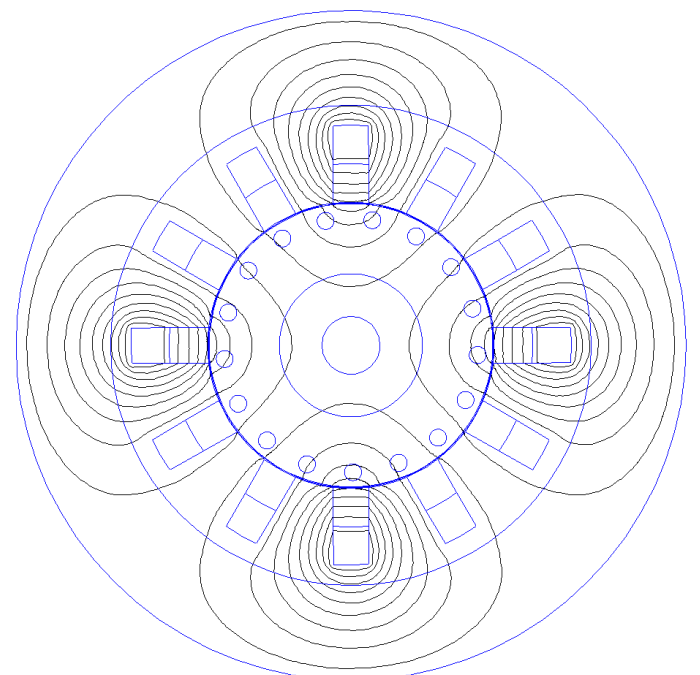

Figure 7. Simulation to determine the leakage inductance of the stator.

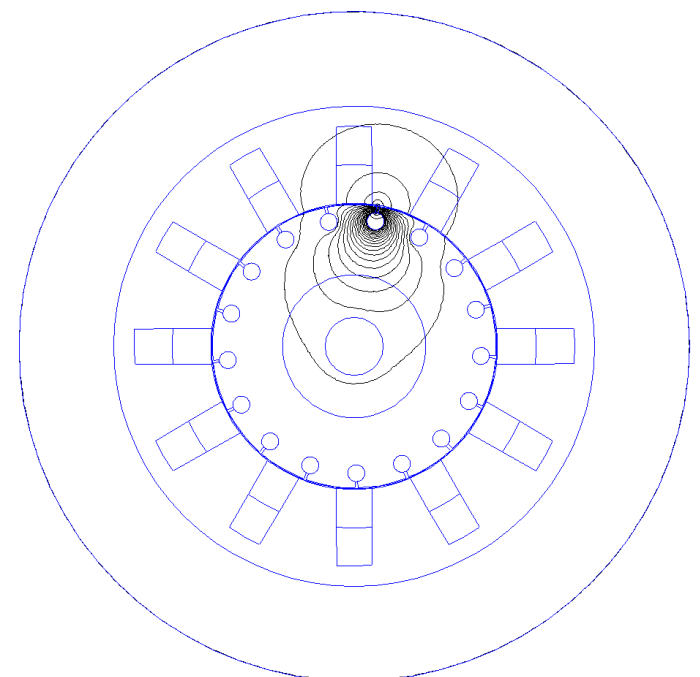

Figure 8. Simulation to determine the leakage inductance of a rotor bar. 


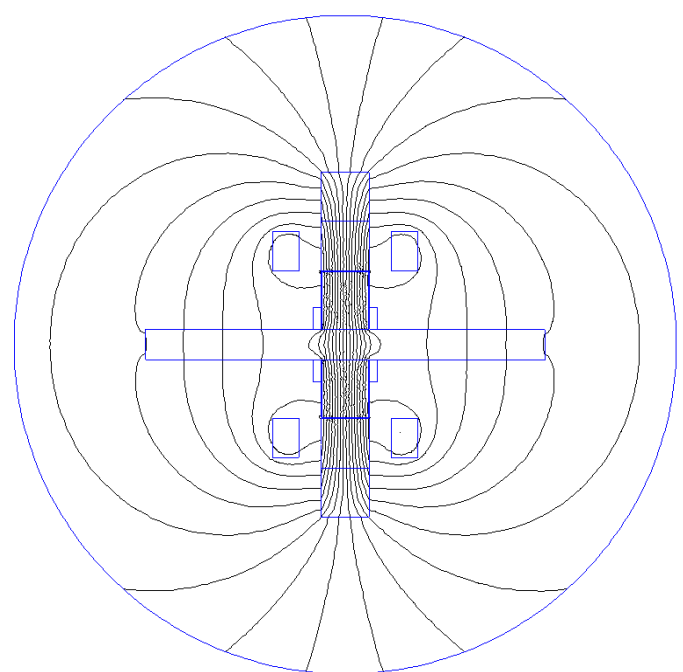

Figure 9. Simulation to determine the leakage inductance of the stator coil head. In this case, the Kelvin transform is applied to improve the contour effect.

In the simulation of Fig. 8, the current in a rotor bar is calculated from equations (1) (2) and (3).

$$
\begin{gathered}
\mathrm{I}_{2}=\mathrm{I}_{2}^{\prime} \cdot \mathrm{r}_{\mathrm{ti}} \\
\mathrm{r}_{\mathrm{ti}}=\frac{\mathrm{N}_{1}}{\mathrm{~N}_{2}} \frac{\mathrm{m}_{1}}{\mathrm{~m}_{2}} \frac{\mathrm{k}_{\mathrm{w} 1}}{\mathrm{k}_{\mathrm{w} 2}} \\
\mathrm{I}_{\mathrm{b}}=\frac{\mathrm{I}_{2}}{\mathrm{p}}
\end{gathered}
$$

Where:

$\mathrm{I}_{2}=$ rotor current

$\mathrm{I}_{2}=$ rotor current referred to stator

$\mathrm{r}_{\mathrm{ti}}=$ current transformation ratio

$\mathrm{N}_{1}=$ number of turns per phase in the stator

$\mathrm{N}_{2}=$ number of turns per phase in the rotor

$\mathrm{m}_{1}=$ number of the stator phases

$\mathrm{m}_{2}=$ number of the rotor phases

$\mathrm{k}_{\mathrm{w} 1}=$ winding factor of the stator

$\mathrm{k}_{\mathrm{w} 2}=$ winding factor of the rotor

$\mathrm{Ib}=$ rotor bar current

$\mathrm{p}=$ number of the pole pairs

The parameters of the equivalent circuit of the rotor referred to the stator $\left(\mathrm{R}^{\prime}{ }_{2}\right.$ and $\left.\mathrm{X}^{\prime} \mathrm{d} 2\right)$ are calculated from the impedance transformation ratio $\left(\mathrm{r}_{\mathrm{tz}}\right)$ which is obtained according to the equation (4).

$$
\mathrm{r}_{\mathrm{tz}}=\left(\frac{\mathrm{N}_{1}}{\mathrm{~N}_{2}}\right)^{2} \frac{\mathrm{m}_{1}}{\mathrm{~m}_{2}}\left(\frac{\mathrm{k}_{\mathrm{w} 1}}{\mathrm{k}_{\mathrm{w} 2}}\right)^{2}
$$

To determine the iron loss resistance, losses in the iron should be approximately estimated. Equation (5) is used, based on the data of the magnetic sheet manufacturer and the induction values obtained in the simulation with finite elements method shown in Figure 10, simulation that is carried out under the same conditions of Figure 6.

$$
\operatorname{Perd}_{\mathrm{Fe}}=\mathrm{k} \cdot \operatorname{Perd}_{\mathrm{Fe} 0} \cdot\left(\frac{\mathrm{f}}{\mathrm{f}_{0}}\right)^{3 / 2} \cdot\left[\mathrm{W}_{\mathrm{d}}\left(\frac{\mathrm{B}_{\mathrm{d}}}{\mathrm{B}_{0}}\right)^{2}+\mathrm{W}_{\mathrm{ce}}\left(\frac{\mathrm{B}_{\mathrm{ce}}}{\mathrm{B}_{0}}\right)^{2}\right]
$$

Where:

PerdFe $=$ iron losses

$\mathrm{k}=$ additional losses coefficient due to the manufacturing process (between 1.5 and 2)

PerdFe 0 specific iron losses $(\mathrm{W} / \mathrm{kg})$ given by the magnetic sheet manufacturer

$\mathrm{f}=$ operation frequency

$\mathrm{f}_{0}=$ frequency in the conditions given by the magnetic sheet manufacturer

$\mathrm{W}_{\mathrm{d}}=$ stator teeth weight

$\mathrm{B}_{\mathrm{d}}=$ maximum flux density in the stator teeth

$\mathrm{B}_{0}=$ maximum flux density in the conditions given by the magnetic sheet manufacturer

$\mathrm{W}_{\mathrm{ce}}=$ stator yoke weight

$\mathrm{B}_{\mathrm{ce}}=$ maximum flux density in the stator yoke

From the simulations carried out according to the Figures 69 and the corresponding calculations carried out, the parameters of the equivalent circuit are obtained as shown in Table 3 .



Figure 10. Simulation to determine the maximum flux densities.

TABLE 3

EQuivalent Circuit ObTained From the Finite Elements Method SIMULATIONS

\begin{tabular}{ll}
\hline \hline \multicolumn{1}{c}{ Parameter } & Value \\
\hline Stator resistance & $16.81 \Omega$ \\
Rotor resistance referred to stator & $15.3 \Omega$ \\
Stator reactance & $25.91 \Omega$ \\
Rotor reactance referred to stator & $25.4 \Omega$ \\
Magnetizing reactance & $134.24 \Omega$ \\
Iron loss resistance & $2381.94 \Omega$ \\
\hline \hline
\end{tabular}

\subsection{Characteristic Curves}

From the parameters of the equivalent circuit, it proceeds to implement the operating equations of the motor in a spreadsheet, a procedure that allows students to solve the 
electrical circuit of the motor and to apply the power balance [19].

In addition, since the equivalent circuit has been obtained by two methods, laboratory tests and simulations with finite elements method, the results obtained by applying the two methods can be shown in the same graph. As an example, Figures 11, 12, 13 and 14 shows the torque-speed characteristic curve, the current-speed characteristic curve, the efficiency curve and the power factor curve, respectively [20].

From the characteristic curves shown in Figures 11, 12, 13 and 14, we can highlight the following aspects:

- the differences between the curves obtained are mainly due to the differences between the equivalent circuit parameters resulting from the laboratory tests with respect to those obtained from the simulations (differences ranging between $1.7 \%$ and $20 \%$. These differences they are caused, mainly, by the approximations in the simulation process, such as simulating in 2D, the existence of parasitic air gaps in the assembly of pieces due to the structure of the didactic equipment,...).

- These differences are greater at specific operating points, such as at start-up (17\%) and at the maximum torque point $(11 \%)$, being smaller in the operating zone around the rated current (minors to the $1 \%$ ).

- Due to the fact that a motor with didactic purposes is used and, therefore, with a structure that is not optimized, the efficiency results and the power factor values are low compared to those would be obtained in the case of using an industrial motor.

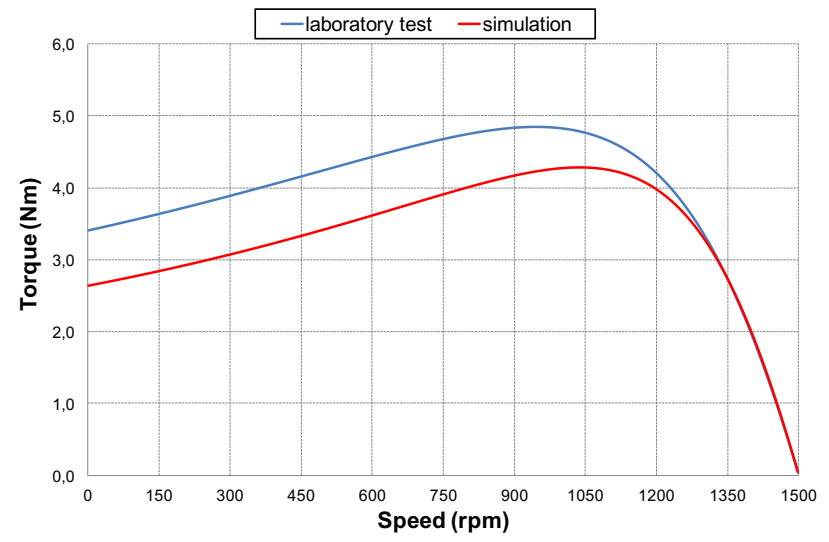

Fig. 11. Torque-speed characteristics obtained with equivalent circuit parameters from laboratory tests and from simulations with finite elements method.

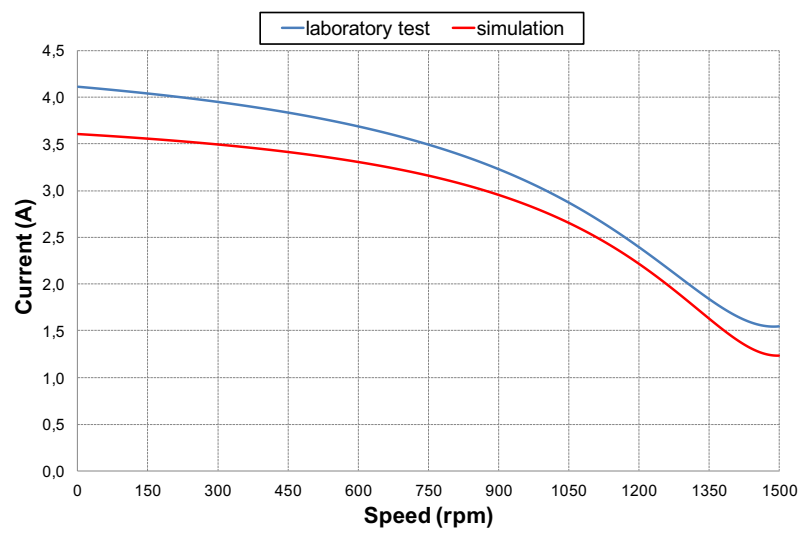

Fig. 12. Current-speed characteristics obtained with equivalent circuit parameters from laboratory tests and from simulations with finite elements method.

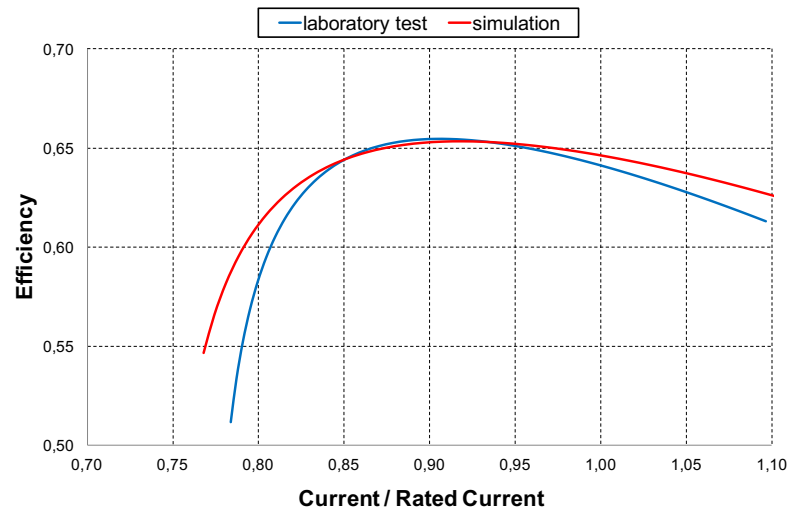

Figure 13. Efficiency characteristics obtained with equivalent circuit parameters from laboratory tests and from simulations with finite elements method.

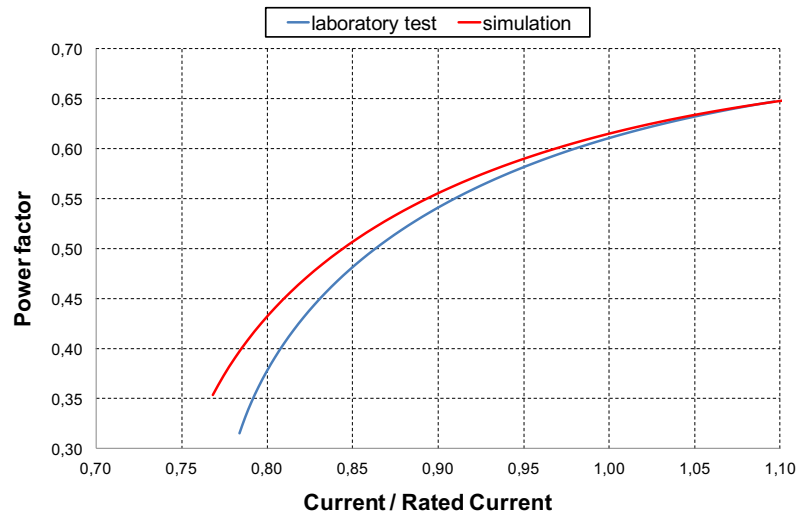

Figure 14. Power factor characteristics obtained with equivalent circuit parameters from laboratory tests and from simulations with finite elements method.

\section{IMPLEMENTATION OF THE APPLICATION WORK IN THE SUBJECT}

This section presents, in an orientative way, how the different parts of the application work shown above are implemented in the development of the subject. Table 4 shows the estimated dedication time for each of the tasks associated with the application work, distinguishing among classroom 
activities, laboratory tests and activities that the student must do without the presence of the teacher. Obviously, the time of the latter is an approximate estimate, since the time needed to perform these activities may vary from one student to another. Carrying out these works in groups of two students has been considered convenient. As shown in Table IV, the total time of dedication estimated to the completion of the application work is 17 hours.

As it is specified, students must elaborate a technical document with the results obtained in the realization of the application work, document that must include the following sections: introduction and objectives, measurements made in the laboratory and derived calculations, simulations through the finite elements method, the characteristic curves obtained, analysis of results, conclusions and bibliography.

In addition, students must prepare an oral presentation of approximately 15 minutes in length. In the classroom, some students will execute the above mentioned presentation and, together with all students of the course, they will participate in a later debate on aspects related to the results obtained and on the realization of the application work.

Within the framework of the subject of electrical machines, and in the curriculum of Graduate in Electrical Engineering (in Escola Politècnica Superior d'Enginyeria de Vilanova i la Geltrú, Universitat Politècnica de Catalunya), where this application work is currently being implemented, the relative time of dedication turns out to be 6 hours out of a total of 60 programmed hours $(10 \%)$ in terms of scheduled classroom activities, that is to say, activities in class and in the laboratory. Whereas the relative time for the student's personal work turns out to be 11 hours out of a total of 90 estimated hours $(12.22 \%)$.

TABLE 4

ESTIMATED TIME DEDICATED TO THE WORK (IN HOURS) BY TASKS

\begin{tabular}{lcc}
\hline \hline \multicolumn{1}{c}{ Activity } & In class & $\begin{array}{c}\text { Out of } \\
\text { class }\end{array}$ \\
\hline $\begin{array}{l}\text { Taking measurements and laboratory tests } \\
\text { Study of the IEC60034-2-1 standard }\end{array}$ & 2 & 2 \\
$\begin{array}{l}\text { Determination of the equivalent circuit } \\
\text { with spreadsheet }\end{array}$ & & 1 \\
$\begin{array}{l}\text { Finite element program management } \\
\text { Simulations with finite elements program }\end{array}$ & 2 & \\
$\begin{array}{l}\text { Determination of characteristic curves } \\
\text { with spreadsheet }\end{array}$ & & 3 \\
$\begin{array}{l}\text { Elaboration of the report } \\
\text { Preparation of the presentation }\end{array}$ & 2 \\
Presentation and discussion of results & 2 & 2 \\
TOTAL & $\mathbf{6}$ & $\mathbf{1 1}$ \\
\hline \hline
\end{tabular}

\section{STUdents FeEdBaCK}

This application work has been done in several courses, although it has been carried out with different variations from one course to another, or even through different activities with a similar methodology. Table 6 shows the number of students who have submitted the application work in the last 5 courses, with its resulting average taking into account the qualifications obtained in the work and the maximum and minimum marks given. The percentage of the qualification obtained in the application work on the final mark for the subject being applied is $12 \%$.

Table 5 shows the work evaluation rubric, a rubric being provided to students before carrying out their work [21] [22].

TABLE 5

EVALUATION RUBRIC OF THE APPLICATION WORK

Quality level
Cutstanding $\quad \begin{array}{r}\text { Introduction and objectives (0.5 points) } \\ \text { What is intended with the completion of the work in all } \\ \text { important aspects is clearly indicated. }\end{array}$
Passing
Failing
Somportant aspect of the work is not properly
reflected, although the main ones are.
What is intended with the work is not indicated.
Laboratory measurements and derivative calculations
(3 points)
All the measures carried out are clearly and coherently
displayed, making use of the corresponding diagrams and
figures. The parameters derived from the tests are
correctly calculated.

Passing The measures taken are displayed, neglecting some important scheme and/or figure. The parameters derived from the trials are mostly correctly calculated.

Failing Variables, schemes and/or important figures are neglected in relation to measurements made. Most of the parameters derived from the tests are incorrectly calculated. Geometry and materials are correctly introduced in the simulation model, properly applying the different conditions in each simulation to obtain results.

Passing The simulation model is mainly correctly introduced, as well as the conditions and the obtaining of results.

Failing Incorrect application of the model and/or simulation conditions, with unsatisfactory obtained results.

Characteristic curves obtained (1.5 points)

Outstanding The calculation procedure for obtaining the characteristic curves is correctly applied, properly indicating the results (graphs,...) so that they can be satisfactorily interpreted (good scales selection, appropriate size, units,...).

Passing

Failing

The calculation procedure is correctly applied, but the results obtained are not satisfactorily interpreted.

Predominantly incorrect calculations, and poor results presentation.

Analysis of results and conclusions (2 points)

Outstanding A reliable criticism of the results obtained is made and the conclusions are consistent with said results.

Passing The criticism about the results obtained is scarce and the conclusions present inconsistencies with those results.

Failing There is no criticism of the results obtained and no conclusions are drawn.

Oral presentation (1 point)

Outstanding Good synthesis in the preparation of the transparencies to prepare the presentation. Active and coherent participation in the discussion of results.

Passing Neglect of important aspects in the transparencies, little elaborated synthesis and little participation in the discussion of the results.

Failing Chaotic and/or incomplete presentation. No participation in the discussion of the results. 
TABLE 6

RESULTS OBTAINED FROM THE APPLICATION WORK EVALUATION (MAXIMUM QUALIFICATION: 10 POINTS)

\begin{tabular}{cccc}
\hline \hline Course & $\begin{array}{c}\text { Number of } \\
\text { students }\end{array}$ & $\begin{array}{c}\text { Average } \\
\text { Qualification }\end{array}$ & $\begin{array}{c}\text { Minimum/ } \\
\text { Maximum } \\
\text { Qualification }\end{array}$ \\
\hline 1 & 15 & 7.15 & $6 / 8.75$ \\
2 & 17 & 6.95 & $5 / 9$ \\
3 & 22 & 6.82 & $5.5 / 8.5$ \\
4 & 35 & 7.17 & $4 / 8.25$ \\
5 & 21 & 6.43 & $3 / 9.25$ \\
\hline \hline
\end{tabular}

\section{CONCLUSIONS}

For the authors, the accomplishment of an application work in Engineering studies, in which different activities must be carried out in the same work (laboratory tests, simulations, study of standards, spreadsheet use, presentation and criticism of results) is an activity of great formative interest.

In the particular case of Electrical Engineering, and more specifically in the field of electrical machines, it allows to cover concepts of a certain complexity, not in an isolated way but in an inclusive and complementary way, stimulating the critical capacity of students during their realization.

The use of didactic material in the laboratory is compatible with the application of regulations and industrial simulation tools.

The preparation of an oral presentation allows the teacher to stimulate students in the need to think about the correct transmission and the criticism of the results.

Preparing a good rubric for the evaluation of the application work allows to adequately guide students on the main aspects to be developed during its realization.

\section{REFERENCES}

[1]T. J. Moore, R. L. Miller, R. A. Lesh, M. S. Stohlmann, Y. R. Kim, "Modeling in engineering: The role of representational fluency in students' conceptual understanding", J. Eng. Educ., vol. 102, no. 1, pp. 141-178, Jan. 2013.

[2] A. J. Magaña, T. de Jong, "Modelling and simulation practices in engineering education", Comp. Appl. in Eng. Educ., vol. 26, no. 4, pp. 731738, June 2018.

[3]D. F. Treagust, R. Duit, "Conceptual change: A discussion of theoretical, methodological and practical challenges for science education", Cult. Stud. Sci. Educ., vol. 3, no. 2, pp. 297-328, 2008.

[4]W. Shyr, C. Lin, "Development of professional competencies for touch screen techniques in electrical engineering", IEEJ Trans. on Electri. and Electro. Eng., vol. 11, no. S1, pp. S24-S27, June 2016.

[5]S. P. Brophy, A. J. Magana, A. Strachan, "Lectures and simulation laboratories to improve learners' conceptual understanding", Adv. Eng. Educ., vol. 3, no. 3, pp. 1-27, 2013

[6]C. A. Canizares, Z. T. Faur, "Advantages and disadvantages of using computer tools in electrical engineering courses," IEEE Trans. on Educ., vol. 40, pp. 166-171, Aug. 1997.

[7]M. del R. Uribe, A. J. Magaña, J. Bahk, A. Shakouri, "Computational simulations as virtual laboratories for online engineering education: A case study in the field of thermoelectricity", Comp. Appl. in Eng. Educ., vol. 24, no. 3, pp. 428-442, Feb. 2016.

[8]T. P. Yildirim, L. Shuman, M. Besterfield-Sacre, "Model-eliciting activities: Assessing engineering student problem solving and skill integration processes", Int. J. Eng. Educ., vol. 26, no. 4, pp. 831-845, 2010.

[9]M. Alptekin, K. Temmen, "Design concept and prototype for an augmented reality based virtual preparation laboratory training in electrical engineering", 2018 IEEE Global Engineering Education Conference (EDUCON), 17-20 Apr. 2018.
[10] I. Boldea, S. Nasar, "The Induction Machine Handboock", CRC Press LLC, New York, 2002.

[11] Electrical Machines Tutor EMT180: Students Course Manual. Feedback Instruments Ltd.

[12] J. J. Cathey, "Electric Machines: Analysis and Design Applying Matlab", Mc Graw-Hill, New York, 2001.

[13] IEC 60034-2-1. Rotating electrical machines. Part 2-1: Standard methods for determining losses and efficiency from tests, 2007.

[14] S. A. Shirsavar, B. A. Potter, I. M. L. Ridge, "Three-Phase Machines and Drives-Equipment for a Laboratory-Based Course", IEEE Trans. on Educ., vol. 49, no. 3, pp. 383-388, Aug. 2006.

[15] S. Ayasun, C. O. Nwankpa, "Induction Motor Tests Using MATLAB/Simulink and Their Integration Into Undergraduate Electric Machinery Courses", IEEE Trans. on Educ., vol. 48, no. 1, pp. 37-46, Feb. 2005.

[16] I. D. Chasiotis, Y. L. Karnavas, "A computer aided educational tool for design, modeling, and performance analysis of Brushless DC motor in post graduate degree courses", Comp. Appl. in Eng. Educ., vol. 26, no. 4, pp. 749767, July 2018

[17] M. H. Nehrir, F. Fatehi, V. Gerez, "Computer modeling for enhancing instruction of electric machinery," IEEE Trans. on Educ., vol. 38,no. 2, pp. 166-170, May 1995.

[18] D. Meeker, "Finite Element Method Magnetics: User's Manual", 2006. [19] J. D. Ortega-Alvarez, W. Sanchez, A. J. Magana, "Exploring Undergraduate Students' Computational Modeling Abilities and Conceptual Understanding of Electric Circuits", IEEE Trans. on Educ., vol. 61, no. 3, pp. 204-213, Aug. 2018.

[20] K. A. Nigim, R. R. DeLyser, "Using MathCad in understanding the induction motor characteristics," IEEE Trans. on Educ., vol. 44, pp. 165-169, May 2001.

[21] B. M. Moskal, "Recommendations for Developing Classroom Performance Assessments and Scoring Rubrics", Practical Assessment Research \& Evaluation, vol. 8, no 14, pp. 1-5, May 2003.

[22] M. Vijayalakshmi, P. D. Desai, G. H. Joshi, "Outcome based education performance evaluation of capstone project using assessment rubrics and matrix", 2013 IEEE International Conference in MOOC, Innovation and Technology in Education (MITE), 20-22 Dec. 2013.

Marcel Torrent was born in Menàrguens, Lleida, Spain, in 1965. He received his Ph.D. degree in Industrial Engineering from Universitat Politècnica de Catalunya (UPC) in 2002. He is currently an Associate Professor within the Department of Electrical Engineering, of EPSEVG (UPC).

Eusebi Martinez was born in Barcelona, Spain, in 1960. He received his Engineering degree in Industrial Engineering from Universitat Politècnica de Catalunya (UPC) in 1984. He is currently an Assistant Professor within the Department of Electrical Engineering, of EPSEVG (UPC).

José Ignacio Perat was born in Tamarite de Litera, Huesca, Spain, in 1965. He received his Ph.D. degree in Industrial Engineering from Universitat Politècnica de Catalunya (UPC) in 2004. He is currently an Associate Professor within the Department of Electrical Engineering, of EPSEVG (UPC). 